\author{
Mediterranean BioMedical Journals \\ Integrative Journal of Medical Sciences \\ 2020, Volume 7, ID 195 \\ DOI: $\underline{10.15342 / \mathrm{ijms} .7 .195}$
}

REVIEW

\title{
Pregnancy and Coronavirus Disease 19
}

\author{
Mythri Shankar a iD, Nishanth KR b \\ a Assistant Professor, Institute of Nephrourology, Bengaluru, India; ${ }^{\mathrm{b}}$ Associate Professor, Rajiv Gandhi University of Health Sciences, Bengaluru, India
}

\begin{abstract}
As Coronavirus disease 2019 (COVID 19) is declared a global pandemic, management of expecting mothers and newborn care becomes a great challenge to the physicians and their families. They should follow the same guidelines as the general population to avoid exposure to the virus as much as possible. Pregnancy does not seem to increase the risk of infection nor accelerate its natural history or the severity of illness. Routine prenatal-antenatal care should be home monitored and telemedicine encouraged as much as possible. Women with comorbidities or at high risk of infection such as a recent history of travel, from a containment zone, history of primary or secondary contact should be closely monitored for symptoms. RT PCR is recommended before labor or one day before elective surgery. Supportive treatment is important in infected patients. Low molecular weight heparin can be used for thromboprophylaxis in severe illness. Data on the use of Remdesivir, Hydroxychloroquine, Lopinavir-Ritonavir are limited. There is limited data on the placental transmission of the virus. The newborn should also be immediately tested following the delivery of a COVID19 pregnant woman. If the newborn is found to be negative, strict hygienic measures according to CDC should be followed to express breast milk. According to WHO, breast milk banks are a safe alternative. Few mothers may prefer to give formula feeds, which can be administered by healthy caregivers. There is limited data regarding the transmission of the virus through breast milk.
\end{abstract}

KEYWORDS: COVID19, Pregnancy, Newborn, Prenatal care, Breast milk.

Correspondence: Dr Mythri Shankar. Institute of Nephrourology, Bengaluru, India. Email: mythri.nish@gmail.com

Copyright (C) 2020 Shankar M \& Nishanth KR. This is an open access article distributed under the Creative Commons Attribution 4.0 International, which permits unrestricted use, distribution, and reproduction in any medium, provided the original work is properly cited.

\section{INTRODUCTION}

Coronavirus disease 2019 (COVID 19) is declared a global pandemic affecting more than a lakh population in more than a hundred countries. It is caused by SARS coronavirus 2 (SARS CoV 2). The first case was declared in Wuhan Province of China on December 31 2019. Since then the disease has spread far and wide. Millions of people are infected worldwide and lakhs of people have died as a consequence. Pregnant women may be at a higher risk due to physiologically suppressed immunity during pregnancy. Also, posing as a major challenge in the care of the newborn.

\section{PREVENTION}

Pregnant women should follow the same precautions as non-pregnant people to avoid exposure to the virus. Such as social distancing, disinfecting surfaces, performing hand hygiene, wearing masks in public places. The monitoring of women with the history of epidemiologic contact should be followed up strictly.
Pregnant women with children should be more vigilant. Mild or asymptomatic infections have been reported in the majority of infected children. They can be superspreaders of the infection. Children from one household should not play around with children from other households. They should maintain six feet distance from other children.[1] They should practice wearing masks in public spaces.

Pregnant health care workers should avoid working in COVID19 treatment establishments. Pregnant workers in non-healthcare occupations can work till term. However, they should work in an environment with a reduced risk of exposure. Fifteen days of quarantine before the date of delivery is recommended. The individual's comorbidities and the scope of work will guide the clinician for requests of medical leave.[2, 3]

\section{CLINICAL MANIFESTATIONS}

All pregnant women should be carefully monitored for symptoms and signs, especially if they are primary or 
secondary contacts of a COVID19 infected case. According to a systematic review, which included 356 studies, the most common symptom was fever $(67 \%)$ followed by cough $(66 \%)$, sore throat $(7 \%)$, breathlessness (7\%) and body ache (6\%). Other symptoms were rhinorrhea, anorexia, headache, loss of taste, and smell. [4]

\section{LAB INVESTIGATIONS}

Lymphopenia (14\%) was seen most commonly, followed by deranged liver function tests $(5 \%)$ and thrombocytopenia (1\%). Severe lymphopenia, increased total leucocyte count, increase in neutrophil count, increase in S. creatinine and blood urea levels were associated with poor prognosis, and an increase in mortality.[5] Cytokine storm caused by viral invasion is a cause for neutrophilia. Sustained inflammation causes coagulation abnormalities. Acute kidney injury can be caused by hypoxia, shock, or direct viral injury.

\section{COMPLICATIONS}

Acute respiratory distress syndrome, myocarditis, shock, disseminated intravascular coagulation [5], thromboembolic complications such as stroke, pulmonary embolism.[6]

\section{COURSE IN PREGNANCY}

According to case series and case reports, pregnancy does not enhance the chances of acquiring infection, does not alter the natural history of the disease and the rate of recovery is the same as the general population. Early delivery is not mandatory for recovery.[7][8] However, elderly pregnant women and those with comorbidities such as obesity are at increased risk of more severe disease. [9] In pregnant women with pneumonia, there is an increased risk of preterm and cesarean delivery. 295 pregnant women were studied in a systematic review [10], out of which $4.7 \%$ required ICU admission. In a study from New York, the United States, 43 pregnant patients were studied. 9.3\% had severe disease and $4.7 \%$ required ICU admission [11]. In China, 147 pregnant patients were studied, illness was severe in $7 \%$ of the patients and critical in 1\%.[12]

Fever and pneumonia can cause hypoxia and increase the risk of premature rupture of membranes and preterm labor. Hyperthermia is one of the symptoms of COVID19. An increase in maternal core temperature can theoretically increase the risk of congenital anomalies such as neural tube defects in the first trimester. However, data on the same are limited. The use of paracetamol for hyperthermia is safe during pregnancy.

\section{VERTICAL TRANSMISSION}

Vertical transmission is not yet proven but the possibility cannot be ruled out. Some of the ways of ensuring fetal safety are by measuring IgM cord blood levels of the virus and testing neonatal nasopharyngeal swab, placental tissue using sterile precautions immediately following delivery. Amniotic fluid can also be tested in case of a cesarean section.
Pregnant women with positive SARS-CoV 2 infection, have tested negative for vaginal and amniotic fluid till date.[13] The percentage of viremia in pregnant women with SARS-CoV2 infection is low [1\%] reducing the incidence of vertical transmission and placental seeding.[14]

A few cases of possible vertical transmission have been reported. But in such cases, Ig $\mathrm{M}$ was positive in the neonate on day 1 or day 2. Vaginal swab and amniotic fluid testing were not done. The infection may be due to postnatal contact with the mother or the caregiver.[15]

Serological tests identify patients who have had prior infections and some patients with ongoing infection (between day 9 to day 14 of symptom onset).[16] They are not useful in the acute setting as it takes 9 to 14 days for antibodies to form. In areas of low seroprevalence, the results should be interpreted with caution. As they have low positive predictive value.[17]

Some kits have obtained emergency use authorization by the FDA.[18] These kits detect antibodies against nucleocapsid and spike antigens of SARS-CoV2. The sensitivity and specificity of these tests are uncertain. They should not be used solely for diagnosis or to rule out SARS-CoV2 infection. The catalog of serological tests is available on www.centerforhealthsecurity.org. CDC recommends using test strips with high specificity $(>99.5 \%)$ and to test in patients with a high pre-test probability of having had the infection earlier. Or else, a two-step method of diagnosis can be used. Confirming the initial positive result with a subsequent different antibody test. Kits based on Ig A antibodies should not be used. The serological tests can cross-react with other coronavirus strains and hence, can have high rates of false-positive tests.[19]

\section{APPROACH TO DIAGNOSIS}

Any patient with:

- New onset of fever/chills and cough/dyspnea

- Pneumonia of unknown etiology

- With travel history prior to 14 days

- History of contact with COVID19 infected patient.

- Residing in the containment zone should be tested with RT-PCR (reverse transcriptase Polymerase chain reaction) for SARS-CoV2-RNA on a nasopharyngeal swab specimen. In areas where the infection is prevalent, pregnant women should be tested when they get admitted for labor or delivery. If a cesarean section is planned, testing can be done one day before the surgery.

\section{DIFFERENTIAL DIAGNOSIS}

If there is a community spread of influenza, it is reasonable to test for influenza infection as well. There can be a coinfection of influenza with SARS-CoV2. Pregnant women can have thrombocytopenia, liver dysfunction, hemolysis as part of HELLP syndrome. Patients with SARS-CoV2 infection may have similar lab abnormalities due to sepsis [20]. Such as,

- Normal or Prolonged PT INR, APTT

- Increased Fibrinogen 
- Increased D-Dimer

- Thrombocytosis or Thrombocytopenia

\section{ROUTINE OBSTETRIC PRENATAL CARE:}

Prior to the visit, pregnant women should take an appointment and use the necessary precautions to reduce the degree of exposure. They should constantly monitor the fetal kick counts and inform immediately in case of decreased fetal movement. As far as possible, teleconsultation should be encouraged.

\section{TREATMENT}

Thromboprophylaxis: Pregnant women with SARSCoV2 infection, should be started on low molecular weight heparin prophylaxis. Unfractionated heparin is preferred over low molecular weight heparin when close to delivery as it has a shorter half-life.

\section{ANTI-VIRAL DRUGS}

Remdesivir: It a nucleotide analog that has in-vitro activity against SARS - CoV2. It is being used on compassionate grounds in pregnant women with severe disease. No reports of fetal toxicity have been found when this drug was used against Ebola Virus.[21, 22]

Hydroxychloroquine: Early randomized studies have shown no benefit. It is known to cause cardiac arrhythmias, especially when combined with other cardiotoxic drugs. Animal studies have shown that it crosses the placenta and causes ocular damage. However, it is not seen in humans. Hydroxychloroquine has been used in pregnant women with systemic lupus erythematous and malaria.[23]

Favipiravir: It is an RNA Polymerase inhibitor. It is contraindicated in pregnancy and lactation at present. Clinical trials are underway in Asia to test the efficacy of the drug. $\{$ NIH 2020A, NIH2020B $\}$

\section{BREASTFEEDING}

Some case reports of SARS-CoV2 being transmitted in breast milk are published [24], there are also few other studies stating otherwise i.e, no evidence of SARS-CoV2 in breast milk. [25] More data are required regarding the transmission of the virus in breast milk.

If the mother is COVID 19 positive and the newborn is negative, she can express breast milk. The expressed breast milk can be fed to the baby by a healthy caregiver. Adequate hygienic measures should be used while expressing the milk, she should clean the breast, nipple, hands with soap and water. She should wear a mask. All

\section{AUTHORS' CONTRIBUTIONS}

The participation of each author corresponds to the criteria of authorship and contributorship emphasized in the Recommendations for the Conduct, Reporting, Editing, and Publication of Scholarly work in Medical Journals of the International Committee of Medical Journal Editors. Indeed, all the authors have actively participated in the redaction, the revision of the manuscript and provided approval for this final revised version. the breast milk collection equipment should be sterilized. $\mathrm{CDC}$ has released guidelines for the safe expression of breast milk.[26]

Global human breast milk banks screen the donor mother, collect, pasteurize, and store breastmilk. It was set up primarily for pre-term, low birth weight babies and babies with congenital anomalies or neurological deficits to improve their immunity and prevent complications [27] In the current Coronavirus Pandemic, WHO has recommended milk from such human breast milk banks as a safe alternative if a mother is unable to feed the baby.[28]

But there are challenges faced by these milk banks such as screening of donor, safe collection of milk, handling risks, transportation, and other logistic problems which need to be taken care of

A Virtual Communication Network of milk bank leaders started to form on March 17, 2020 and now has more than 80 members from 34 countries.[29]

If both mother and infant are positive for infection, separation is not necessary.[30]

If women choose to administer formula feed, the healthy caregiver is preferred for the same.

\section{CONCLUSION}

Pregnant women should follow the same recommendations as the general population to avoid exposure to SARS-CoV2. Clinical symptoms are similar to the general population. Women with a severe infection such as pneumonia may have complications like premature rupture of membranes and preterm delivery. Women with preterm mild COVID 19 infection do not require early delivery. Delivery can be planned once the patient becomes negative for the infection and in isolation. Only for women with severe COVID 19 illness with pneumonia, early delivery at least at 32 to 34 weeks can be planned. In areas where the infection is prevalent, pregnant women should be tested when they get admitted for labor or delivery. If a cesarean section is planned, testing can be done one day before the surgery. If the mother is COVID 19 positive and the newborn is negative, she can express the breast milk. The expressed breast milk can be fed to the baby by a healthy caregiver. Adequate hygienic measures should be used while expressing milk. WHO has recommended pasteurized milk from human breast milk banks as a safe alternative if a mother is unable to feed the baby.

\section{SPONSORSHIP}

Declared none.

\section{COMPETING INTERESTS}

The authors declare no competing interests with this study. 


\section{REFERENCES}

[1] United States Centers for Disease Control and Prevention. Coronavirus disease 2019 (COVID-19). Caring for children.Georgia.2020. Available from: https://www.cdc.gov/coronavirus/2019-ncov/dailylife-coping/children.html (Accessed on May 31, 2020)

[2] American College of Obstetricians and Gynecologists. COVID-19 FAQs for obstetriciansgynecologists, obstetrics. Washington, DC: ACOG; 2020. Available at: https://www.acog.org/clinicalinformation/physician-faqs/covid-19-faqs-for-obgyns-obstetrics.(Accessed on June1, 2020)

[3] Royal College of Obstetricians and Gynecologists. COVID-19 virus infection and pregnancy. Occupational health advice for employers and pregnant women during the COVID-19 pandemic.United Kingdom.2020.Available from: https://www.rcog.org.uk/en/guidelines-researchservices/guidelines/coronavirus-pregnancy/covid19-virus-infection-and-pregnancy. (Accessed on May31,2020)

[4] Stokes EK, Zambrano LD, Anderson KN, Ellyn P. Marder, Kala M. Raz, Suad El Burai Felix. Coronavirus Disease 2019 Case Surveillance United States, January 22-May 30, 2020. MMWR Morb Mortal Wkly Rep. ePub: 15 June 2020.

[5] Wang D, Hu B, Hu C, Zhu F, Liu X, Zhang J et al. Clinical Characteristics of 138 Hospitalized Patients With 2019 Novel Coronavirus-Infected Pneumonia in Wuhan, China. JAMA. $2020 \mathrm{Feb}$ 7;323(11):1061-9.

[6] Danzi GB, Loffi M, Galeazzi G, Gherbesi E. Acute pulmonary embolism and COVID-19 pneumonia: a random association? Eur Heart J. 2020 May 14;41(19):1858.

[7] Breslin N, Baptiste C, Miller R, Fuchs K, Goffman $\mathrm{D}$, Gyamfi-Bannerman $\mathrm{C}$ et al. Coronavirus disease 2019 in pregnancy: early lessons. Am J Obstet Gynecol MFM. 2020 May;2(2):100111.

[8] $\mathrm{Wu} \mathrm{Z,} \mathrm{McGoogan} \mathrm{JM.} \mathrm{Characteristics} \mathrm{of} \mathrm{and}$ Important Lessons From the Coronavirus Disease 2019 (COVID-19) Outbreak in China: Summary of a Report of 72314 Cases From the Chinese Center for Disease Control and Prevention. JAMA. 2020 Feb 24.

[9] Huntley BJF, Huntley ES, Di Mascio D. Rates of Maternal and Perinatal Mortality and Vertical Transmission in Pregnancies Complicated by Severe Acute Respiratory Syndrome Coronavirus 2 (SARS-Co-V-2) Infection: A Systematic Review. Obstetrics and Gynecology. 2020 Jun.

[10] Juan J, Gil MM, Rong Z, Zhang Y, Yang H, Poon LC. Effects of coronavirus disease 2019 (COVID19) on maternal, perinatal and neonatal outcomes: a systematic review. Ultrasound Obstet Gynecol. 2020 May 19:10.1002/uog.22088.
[11] Breslin N, Baptiste C, Gyamfi-Bannerman C, Miller R, Martinez R, Bernstein K et al. COVID-19 infection among asymptomatic and symptomatic pregnant women: Two weeks of confirmed presentations to an affiliated pair of New York City hospitals. Am J Obstet Gynecol MFM. 2020 Apr 9;2(2):100118.

[12] World Health Organisation.Report of the WHOChina Joint Mission on Coronavirus Disease 2019 (COVID-19).Geneva.16-24 February 2020.Available from: https://www.who.int/docs/defaultsource/coronaviruse/who-china-joint-mission-oncovid-19-final-report.pdf (Accessed on June 14, 2020).

[13] Yan J, Guo J, Fan C, Juan J, Yu X, Li J et al. Coronavirus disease 2019 in pregnant women: a report based on 116 cases. Am J Obstet Gynecol. 2020 Apr 23:S0002-9378(20)30462-2.

[14] Wang W, Xu Y, Gao R, Lu R, Han K, Wu G et al. Detection of SARS-CoV-2 in Different Types of Clinical Specimens. JAMA. 2020 Mar 11;323(18):1843-4.

[15] Dong L, Tian J, He S, Zhu C, Wang J, Liu C et al. Possible Vertical Transmission of SARS-CoV-2 From an Infected Mother to Her Newborn. JAMA. 2020 Mar 26;323(18):1846-8.

[16] Fang FC, Naccache SN, Greninger AL. The Laboratory Diagnosis of COVID-19-- FrequentlyAsked Questions. Clin Infect Dis. 2020 Jun 8.

[17] Bryant JE, et al. Serology for SARS-CoV-2: Apprehensions, Opportunities, and the Path Forward. Sci Immunol. 202005 19;5(47).

[18] US Food and Drug Administration. Emergency Use Authorizations.Maryland.2020.Available from: https://www.fda.gov/medical-devices/emergencysituations-medical-devices/emergency-useauthorizations (Accessed on June 16, 2020).

[19] Centers for Disease Control and Prevention. Interim Guidelines for COVID-19 Antibody Testing in Clinical and Public Health Settings. Georgia. 2020.Available from: https://www.cdc.gov/coronavirus/2019ncov/lab/resources/antibody-testsguidelines.html?deliveryName $=$ USCDC_2067DM29085 (Accessed on May 26, 2020).

[20] Tang N, Li D, Wang X, Sun Z. Abnormal coagulation parameters are associated with poor prognosis in patients with novel coronavirus pneumonia. J Thromb Haemost. 2020 Apr;18(4):844-847.

[21] Wang M, Cao R, Zhang L, Yang X, Liu J, Xu M,et al. Remdesivir and chloroquine effectively inhibit the recently emerged novel coronavirus (2019$\mathrm{nCoV}$ ) in vitro. Cell Res. 2020 Mar;30(3):269-271. 
[22] Mulangu S, Dodd LE, Davey RT Jr, Tshiani Mbaya O, Proschan M, Mukadi D et al; PALM Consortium Study Team. A Randomized, Controlled Trial of Ebola Virus Disease Therapeutics. N Engl J Med. 2019 Dec 12;381(24):2293-2303

[23] Lacroix I, Bénévent J, Damase-Michel C. Chloroquine and hydroxychloroquine during pregnancy: What do we know? Therapie; 2020 May 11:S0040-5957(20)30093-7.

[24] Wu Y, Liu C, Dong L, Zhang C, Chen Y, Liu J et al. Coronavirus disease 2019 among pregnant Chinese women: case series data on the safety of vaginal birth and breastfeeding. BJOG. 2020 May 5.

[25] Liu W, Wang J, Li W, Zhou Z, Liu S, Rong Z. Clinical characteristics of 19 neonates born to mothers with COVID-19. Front Med. 2020 Apr;14(2):193-198.

[26] Centers for Disease Control and Prevention. Interim Considerations for Infection Prevention and Control of Coronavirus Disease 2019 (COVID-19) in Inpatient Obstetric Healthcare Settings.Georgia.2020. Available from: https://www.cdc.gov/coronavirus/2019- ncov/hcp/inpatient-obstetric-healthcareguidance.html (Accessed on April 09, 2020).

[27] Quigley M, Embleton ND, McGuire W. Formula versus donor breast milk for feeding preterm or low birth weight infants. Cochrane Database Syst Rev. 2018 Jun 20;6(6):CD002971

[28] WHO. Donor human milk for low-birth-weight infants. Geneva. 2019. Available from: https://www.

who.int/elena/titles/donormilk_infants/en/ (accessed April 30, 2020)

[29] Natalie Shenker.Maintaining safety and service provision in human milk banking: a call to action in response to the COVID-19 pandemic.Lancet.2020 July 01;4(7)484-485.

[30] American academy of pediatrics.Breastfeeding Guidance Post Hospital Discharge for Mothers or Infants with Suspected or Confirmed SARS-CoV-2 Infection.Itasca,IL USA.2020. Available from: https://services.aap.org/en/pages/2019-novelcoronavirus-covid-19-infections/breastfeedingguidance-post-hospital-discharge/ (Accessed on June 20, 2020). 